\title{
Liquid phase transformation of $\alpha$-pinene over Beta zeolites containing aluminium or boron, titanium and vanadium as lattice ions
}

\author{
G. Gündüz ${ }^{\mathrm{a}, *}$, R. Dimitrova ${ }^{\mathrm{b}}$, S. Yilmaz ${ }^{\mathrm{c}}$, L. Dimitrov $^{\mathrm{d}}$ \\ ${ }^{a}$ Department of Chemical Engineering, Ege University, 35100 Bornova, Izmir, Turkey \\ ${ }^{\mathrm{b}}$ Institute of Organic Chemistry, Bulgarian Academy of Sciences, lll3 Sofia, Bulgaria \\ ${ }^{\mathrm{c}}$ Department of Chemical Engineering, Izmir Institute of Technology, Izmir, Turkey \\ ${ }^{\mathrm{d}}$ Centro de Ciências Exatas e de Tecnologia, University Federal de São Carlos, São Carlos, Brazil
}

Received 18 August 2004; received in revised form 30 November 2004; accepted 30 November 2004

Available online 8 January 2005

\begin{abstract}
Beta zeolites with different modules $\left(\mathrm{SiO}_{2} / \mathrm{Al}_{2} \mathrm{O}_{3}\right)$ and containing $\mathrm{B}$, Ti or $\mathrm{V}$ in lattice positions were synthesised by different methods and tested as catalysts in liquid phase transformation of $\alpha$-pinene at $100{ }^{\circ} \mathrm{C}$ in a batch reactor. It was established that the hydrogen forms of Beta samples with a $\mathrm{SiO}_{2} / \mathrm{Al}_{2} \mathrm{O}_{3}$ module of about 55-66 and containing both micro- and mesopores displayed high catalytic activity in liquid phase isomerization of $\alpha$-pinene. Samples with boron, titanium or vanadium, as lattice ions possess insignificant catalytic activity.

(C) 2004 Elsevier B.V. All rights reserved.
\end{abstract}

Keywords: $\alpha$-Pinene; Beta zeolite; Al-Beta; B-Beta; Ti-Beta; V-Beta; Liquid phase; Camphene

\section{Introduction}

$\alpha$-Pinene is a very reactive substrate. Mono-, bi- and triocyclic products are formed as a result of the isomerization of $\alpha$-pinene in presence of acid catalysts, in parallel and irreversible steps. Many heterogeneous catalysts such as titanium dioxide, clays, halloysite, natural and synthetic zeolites, activated carbon, silica-supported rare earth oxides and sulphated zirconia are examined for $\alpha$-pinene isomerization [1-3]. In our previous studies, liquid phase isomerization of $\alpha$-pinene has been investigated over clinoptilolite based natural zeolites, which is the most abundant deposits occurred at Western Anatolia region of Turkey and over natural clays (nonswelling montmorillonite) $[1,4,5]$. It is established that the main reaction products are camphene and limonene. Tricyclene, terpinolene, $p$ cymene, $\alpha$ - and $\gamma$-terpinene are also formed. The selectivity to bi- and tricyclic products is almost independent of conversion, whereas selectivity to limonene depends on $\alpha$ -

\footnotetext{
* Corresponding author. Tel.: +90 232 3884000/2292; fax: +90 2323887776

E-mail address: gunduz@eng.ege.edu.tr (G. Gündüz).
}

pinene conversion. At relatively high conversions, $80-85 \%$, limonene is transformed into secondary products. The acidic pre-treatment of the natural clays improve their catalytic activity. Camphene and bicyclic products are preferentially formed on Lewis sites (L), while the monocyclic products are preferentially formed on Brönsted sites (B). When the ratio $\mathrm{L} / \mathrm{B}$ is high enough the selectivity to camphene grows significantly [6]. The formation of heavy products increases with the samples pre-treatment temperature [7]. Due to the significant differences in the kinetic diameters of $\alpha$-pinene and the above-mentioned reaction products, the $\alpha$-pinene isomerization is used as a model reaction to assess the influence of samples pore accessibility on the catalyst selectivity.

It is known that the lattice of Beta zeolite is a specific combination of Brönsted, Lewis acid sites and framework defects depending on the procedure used for Beta zeolite synthesis, template removal and activation [8,9]. Methanol conversion and $\alpha$-pinene isomerization had been applied as test reactions for estimation of centres acidic function $[10,11]$. It was found that the hydrogen forms of Beta zeolites with micro-/mesopores revealed an excellent activity in pinene isomerization. On contrary, the hydrogen 
forms of the microporous Beta samples showed low activity, despite their high acidity, most probably because of hindrance effect [11]. The data in the literature revealed that the boron analogue of Beta zeolite possessed low catalytic activity in the hydration and isomerization of $\alpha$ pinene [12]. Ti-Beta zeolite was examined in the rearrangement of $\alpha$-pinene oxide to campholenic aldehyde [13] and was found that it was an effective catalyst for the selective production of campholenic aldehyde.

Although there are many studies on the synthesis and characterisation of bimodal molecular sieves containing both micro- and/or mesoporous [14-16], data on its catalytic properties towards bulky hydrocarbons are still rather scare $[12,13,17]$. The objective of the presented work has been to analyse the influence of the silica module variation, the isomorphous incorporation of boron, vanadium or titanium as lattice ions and the procedure of Beta zeolite synthesis on its acidity and catalytic activity in $\alpha$-pinene isomerization.

\section{Experimental}

\subsection{Catalysts preparation and characterisation}

Beta zeolites with different modules $\left(\mathrm{SiO}_{2} / \mathrm{Al}_{2} \mathrm{O}_{3}\right)$ and containing $\mathrm{Al}$ or $\mathrm{B}$, Ti or $\mathrm{V}$ in lattice positions were synthesized by hydrothermal crystallisation of appropriate gels as described by Lohse et al. [18]. The obtained samples were denoted as B-Beta(20), Al-Beta(20), Al-Beta(55), AlBeta(130), Ti-Beta(130) and V-Beta(20), the number in the bracket shows the corresponding module. The obtained samples were washed with deionized water, dehydrated at $523 \mathrm{~K}$ for $2 \mathrm{~h}$ and then calcined up to $823 \mathrm{~K}$ (with a temperature ramp of $1 \mathrm{~K} \mathrm{~min}^{-1}$ ) under a dry air flow of $80 \mathrm{ml} / \mathrm{min}$. Further on, an exchange with a $0.1 \mathrm{M} \mathrm{NH}_{4} \mathrm{Cl}$ solution $(100 \mathrm{ml})$ at $363 \mathrm{~K}$ for $1 \mathrm{~g}$ sample was carried out to prepare the hydrogen forms. The synthesized Al-Beta(55) sample was first oven dried and calcined at $723 \mathrm{~K}$ and then subjected to the ion exchange procedure.

The Al-Beta(66) sample was synthesized according to the steam-assisted crystallization method as described by Matsukate et al. [19]. Samples denoted as mAl-Beta(6648 ) and $m \mathrm{Al}-\mathrm{Beta}(66-113)$ were assembled from Beta zeolite seeds. The first number in the brackets stands for the $\mathrm{SiO}_{2} / \mathrm{Al}_{2} \mathrm{O}_{3}$ module while the second shows the different times of mesostructuring (h) [20].

XRD studies were done on a Philips PW 1840 diffractometer, equipped with a PW 1830 generator in the regions of $2 \theta\left(5-10^{\circ}, 22.5-25^{\circ}\right)$. The SEM microphotographs are taken on Philips XL 30S-model scanning electron microscope and reveal well-grown crystal grains. The surface areas and the pore volumes of the samples were obtained from the nitrogen adsorption isotherms measured at $77 \mathrm{~K}$ in a static volumetric apparatus (Coulter Omnisorp 100CX) up to $P / P_{0} \sim 0.95$. Nitrogen adsorption data were evaluated as the monolayer surface area and half width of pores were calculated by using Langmuir and Dubinin-Astakhov (D-A) methods [21,22]. Temperature programmed desorption of ammonia (TPDA) was performed in a conventional flow reactor supplied with a thermal conductivity detector. The precise procedure had been described in [23]. The sample characteristics are summarized in Table 1.

\subsection{Catalytic test}

All catalysts were tested in the reaction of $\alpha$-pinene isomerization. The experiments were carried out at atmospheric pressure under nitrogen flow in a glass reactor with a reflux condenser, an efficient stirrer and a temperature controller. For a typical run, $0.5 \mathrm{~g}$ of catalyst and $25 \mathrm{ml}$ of $\alpha$ pinene (Acros) were charged into the reactor. After charging the catalyst, the reaction was started and temperature was kept constant at $373 \mathrm{~K}$ along the duration of the run. Samples were taken periodically during the course of the reaction and

Table 1

Characteristics of samples

\begin{tabular}{|c|c|c|c|c|c|c|c|c|c|c|c|}
\hline Samples & $\begin{array}{l}V_{\text {micro }} \\
(t-\text { plot }) \\
\left(\mathrm{cm}^{3} / \mathrm{g}\right)\end{array}$ & $\begin{array}{l}A_{\text {micro }}{ }^{2} \\
(t \text {-plot }) \\
\left(\mathrm{m}^{2} / \mathrm{g}\right)\end{array}$ & $\begin{array}{l}A_{\text {ext }} \\
(t-\text { plot }) \\
\left(\mathrm{m}^{2} / \mathrm{g}\right)\end{array}$ & $\begin{array}{l}A_{\text {Langmuir }} \\
\left(\mathrm{m}^{2} / \mathrm{g}\right)\end{array}$ & $\begin{array}{l}A_{\mathrm{BET}} \\
\left(\mathrm{m}^{2} / \mathrm{g}\right)\end{array}$ & $\begin{array}{l}\text { Total volume of } \\
\text { micropore system, } \\
W_{0}\left(\mathrm{~cm}^{3} / \mathrm{g}\right)\end{array}$ & $\begin{array}{l}\text { Average of } \\
\text { half width of } \\
\text { pores }(\mathrm{nm})\end{array}$ & $n$ & $\begin{array}{l}V_{\max }^{\mathrm{b}} \\
\left(\mathrm{cm}^{3} / \mathrm{g}\right)\end{array}$ & $\begin{array}{l}\text { Total } \\
\text { pore volume } \\
(\mathrm{ml} / \mathrm{g})\end{array}$ & $\begin{array}{l}\text { Desorbed } \\
\mathrm{NH}_{3} \\
(\mathrm{mg} \text { egv) }\end{array}$ \\
\hline B-Beta(20) & 0.0683 & 155.4 & 66.5 & 306.6 & 221.9 & 70.14 & 0.913 & 1.59 & 167.8 & 0.1457 & 0.46 \\
\hline Al-Beta(20) & 0.172 & 357.4 & 43.3 & 553.7 & 400.7 & 123.4 & 0.501 & 3.79 & 167.26 & 0.0632 & 1.34 \\
\hline Al-Beta(130) & 0.1611 & 341.5 & 47.5 & 533.8 & 389.0 & 116.12 & 0.512 & 3.88 & 155.14 & 0.0557 & 0.43 \\
\hline Ti-Beta $(130)^{c}$ & 0.0394 & 96.86 & 77.06 & 240.5 & 173.9 & 239.6 & 0.987 & 1.91 & 485.63 & 0.7085 & 1.75 \\
\hline V-Beta $(20)^{\mathrm{d}}$ & - & - & 140.8 & 182.0 & 129.9 & 145.4 & 1.296 & 2.28 & 275.9 & 0.4715 & 1.17 \\
\hline $\mathrm{Al}-\mathrm{Beta}(55)^{\mathrm{e}}$ & 0.182 & 385.3 & 227.7 & 837.3 & 612.9 & 184.8 & 0.672 & 1.94 & 626.01 & 0.7431 & 1.75 \\
\hline Al-Beta(66) & 0.018 & 47.2 & 182.7 & 319.7 & 229.9 & 71.5 & 1.08 & 1.41 & 617.56 & 0.955 & 1.32 \\
\hline meso-Beta(66-48) & - & - & 985.5 & 1052.6 & 758.9 & 238.3 & 1.066 & 1.40 & 613.43 & 0.7662 & 1.09 \\
\hline meso-Beta(66-113) & _- & _- & 768.1 & 942.4 & 676.0 & 214.1 & 1.062 & 1.28 & 509.42 & 0.5363 & 1.25 \\
\hline
\end{tabular}

${ }^{\mathrm{a}} A_{\text {micro }}=A_{\mathrm{BET}}-A_{t \text {-plot }}$.

${ }^{\mathrm{b}}$ At $P / P_{0}=0.983$.

c Titanium content about $2.5 \%$, as estimated by elemental analysis.

${ }^{\mathrm{d}}$ Vanadium content about $1.1 \%$, as estimated by elemental analysis.

${ }^{\mathrm{e}}$ Calcined at $823 \mathrm{~K}$ in an oven before transformation into hydrogen form. 
analysed with a gas chromatograph (Hewlett-Packard 5980/ 2 with $25 \mathrm{~m}$ and $0.32 \mathrm{~mm}$ i.d. HP-FFAP capillary column) equipped with flame ionization detector (FID). Temperature programming (increase at a rate of $2{ }^{\circ} \mathrm{C} / \mathrm{min}$ from 333 to $403 \mathrm{~K}$ and onwards at a rate $3{ }^{\circ} \mathrm{C} / \mathrm{min}$ until $500 \mathrm{~K}$ ) was applied for separation at $1 \mathrm{ml} / \mathrm{min}_{2}$ flow. A kinetic run took $3 \mathrm{~h}$.

\section{Results and discussion}

The adsorption isotherms of the investigated Beta zeolites are given in Fig. 1. As it is seen, the isotherms are mainly of type II (the Brunauer, Deming and Teller (BDDT) classification) with the exception of the isotherms of sample Al-Beta(20) (that is of type I) and of meso-Beta samples (those are of type IV) (Fig. 1a). It is well known that isotherm of type I corresponds to a complete monolayer formation and is typical for microporous materials. The isotherm of type II corresponds to multilayer formation and is commonly obtained in the case of physical adsorption. The isotherms of type IV reflect the existance of a capillary condensation. So, it could be stated that samples with rather
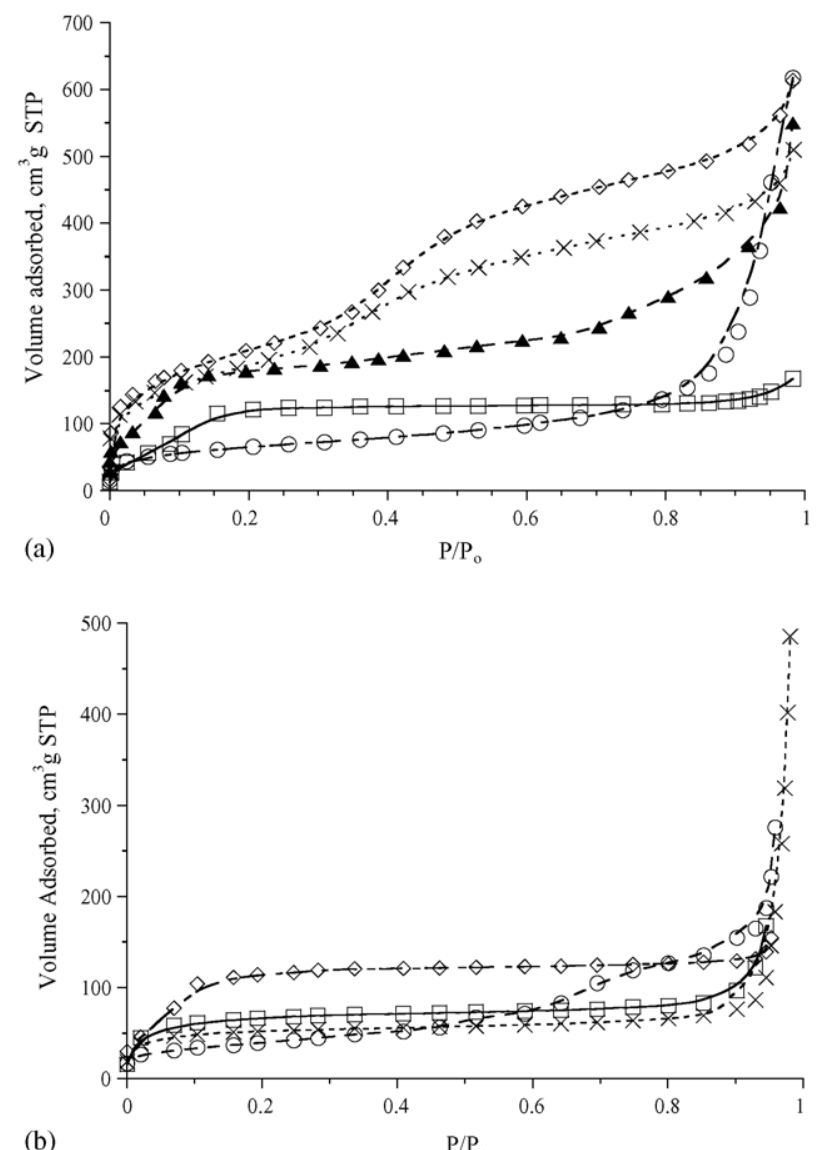

Fig. 1. Nitrogen adsorption isotherms of catalysts: (a) ( $\square$ ) Al-Beta(20);

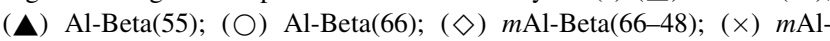
Beta(66-113). (b) ( $\square)$ B-Beta(20); $(\diamond)$ Al-Beta(130); $(\times)$ Ti-Beta(130); (O) V-Beta(20). different characteristics could be obtained by varying the methods of zeolite synthesis or template removal.

Langmuir, BET, Dubinin-Astakhov (D-A) and $t$-plot equations have been used for the evaluation of the sorption experimental data (Table 1$)$. The micropore volume $\left(V_{\text {micro }}\right)$ and the external surface area $\left(A_{\text {ext }}\right)$ are calculated from the $t$ plot. The total volume of the micropore system $\left(W_{0}\right)$ and the exponential constant $\mathrm{n}$ in the $\mathrm{D}-\mathrm{A}$ equation were determined also. The $n$-value in the $\mathrm{D}-\mathrm{A}$ equation could be related to heterogeneity of samples with respect to the pore size distribution. It is known that if the $n$-value decreases, heterogeneity of the pore increases. As it is seen the incorporation of boron and vanadium as lattice ions increases the external surface area of Al-Beta(20) from 43.3 to $66.5 \mathrm{~m}^{2} / \mathrm{g}$ (for B-Beta(20) sample) and to $140.8 \mathrm{~m}^{2} / \mathrm{g}$ (for V-Beta(20)). A similar increase in the external surface area of Al-Beta(130) is observed with titanium incorporation in the Beta zeolite framework, Ti-Beta(130) sample. The complete substitution of aluminium by boron or vanadium and its partial substitution by titanium increase the total pore volume of the samples too. The highest total pore volume was obtained for samples Al-Beta(66). The SEM microphotographs and XRD patterns revealed that samples growth and crystallinity were satisfactory.

The external surface areas of the mesoporous samples, $m \mathrm{Al}-\mathrm{Beta}(66-48)$ and $m \mathrm{Al}-\mathrm{Beta}(66-113)$, are increased four to five times in comparison with the one of samples $\mathrm{Al}$ Beta(55) and Al-Beta(66) that are with an approximately equal module. It is observed, as well, that at longer time of mesostructuring, a lower total pore volume is obtained. The calculated $n$-values for the Beta samples with $\mathrm{B}, \mathrm{Ti}$ or $\mathrm{V}$ in lattice positions are less than for the corresponding $\mathrm{Al}$ containing Beta samples. With the increase $\mathrm{SiO}_{2} / \mathrm{Al}_{2} \mathrm{O}_{3}$ module of samples from 20 to 66 a continuous decrease of the $n$-value from 3.79 to 1.41 is observed revealing an increased heterogeneity in the pore size distribution.

The complete exchange of aluminium by boron leads to a drastic decrease in the total sample acidity (Table 1), while the substitution of aluminium by titanium, Ti-Beta(130), leads to a sharp increase of the total acidity. In the case of VBeta(20), the latter is comparable with the acidity of AlBeta(20). Thus, it is proved the strong relation between Beta zeolite composition and acidity. A deviation of the rule is found for sample Beta(55). Since, the calcination is done in an oven at $770 \mathrm{~K}$ it is believed that a dehydroxylation and formation of predominantly adjacent defect sites (internal silanol groups) were obtained. The presence of the latter could explain the acidic sites number of sample Beta(55) in excess of its aluminium content. The method of Beta zeolite synthesis does not strongly affect the total acidity of samples. The latter is determined to be almost the same for all samples with a module of 66 . Nevertheless, the calculated values for sites acid strength, based on its silica module and the amount desorbed ammonia, significantly differ [10].

The found differences in textural characteristics of Beta zeolites had been well perceived in the catalytic experiments 
Table 2

$\alpha$-Pinene conversion $\left(X_{\alpha}\right)$ and weight percentages of compounds after $3 \mathrm{~h}$ reaction

\begin{tabular}{|c|c|c|c|c|c|c|c|c|c|c|c|c|}
\hline Catalysts & $X_{\alpha}$ & 1 & 2 & 3 & 4 & 5 & 6 & 7 & 8 & LRTP & UP & HRTP \\
\hline B-Beta(20) & 2.68 & - & 97.30 & & 0.32 & - & - & - & - & - & - & 2.65 \\
\hline $\operatorname{Al}-\operatorname{Beta}(20)$ & 6.56 & - & 93.07 & 0.54 & 3.08 & - & 2.43 & & 0.44 & - & 0.45 & - \\
\hline Al-Beta(55) & 99.24 & 7.64 & 0.74 & 4.20 & 27.58 & 13.37 & - & 5.94 & 5.69 & 0.53 & 2.60 & 31.71 \\
\hline Al-Beta(130) & 0.63 & - & 98.82 & - & 0.30 & - & - & - & - & & - & 0.88 \\
\hline Ti-Beta(130) & 0.76 & - & 98.99 & - & 0.38 & - & - & - & - & - & - & 0.63 \\
\hline V-Beta(20) & 2.85 & - & 96.93 & - & 0.23 & - & - & - & - & - & - & 2.84 \\
\hline Al-Beta(66) & 1.70 & 0.23 & 96.70 & - & 0.92 & - & - & 0.22 & - & - & - & 1.94 \\
\hline meso-Beta(66-48) & 99.32 & 5.83 & 0.65 & 5.12 & 26.20 & 18.58 & 4.82 & 6.55 & 11.40 & 1.07 & 3.15 & 16.64 \\
\hline meso-Beta(66-113) & 99.37 & 6.16 & 0.57 & 5.09 & 25.93 & 20.31 & 2.52 & 6.54 & 9.99 & 0.96 & 3.30 & 18.63 \\
\hline
\end{tabular}

1, tricyclene; 2, $\alpha$-pinene; 3, fenchenes; 4, camphene; 5, terpinenes; 6 , limonene; $7, p$-cymene; 8 , terpinolenes.

with $\alpha$-pinene. The overall conversion of $\alpha$-pinene and the composition of reaction mixtures after a reaction time of $3 \mathrm{~h}$ are presented in Table 2. Products with a retention time lower than $\alpha$-pinene are designated as LRTP (low retention time products), those with higher retention times than terpinolene as HRTP (high retention time products) and unidentified products in the range between $\alpha$-pinene and terpinolene as "UP". As it is seen, Al-Beta(55) and mesoBeta zeolites are very active in $\alpha$-pinene isomerization. An almost complete conversion is reached over these catalysts. Catalysts denoted as Al-Beta(130), Ti-Beta(130) and AlBeta(66) are inactive, while the conversion of $\alpha$-pinene over B-Beta(20), Al-Beta(20) and V-Beta(20) is low. Having in mind that $\alpha$-pinene isomerization occurs on Brönsted acidic sites $[2,6]$, it is easy to explain the low activity of B-Beta(20) and Al-Beta(130). Ti-Beta(130) samples possesses Lewis acidity [16] that seems not to be appropriate for the $\alpha$-pinene isomerization. Although V-Beta(20) and Al-Beta(20) samples display a high Brönsted acidity, they are not active in $\alpha-$ pinene isomerization. Most probably this is due to the difficult accessibility of the acid sites.

As it is seen from Table 2, the limonene weight fraction decreases over the following catalysts with order: $m \mathrm{Al}$ $\operatorname{Beta}(66-48)>m$ Al-Beta(66-113) $>$ Al-Beta(55). At the same time, it should be marked that the weight percentages of terpinenes, terpinolenes and HRTP increase in a following order: Al-Beta(55) $<m \mathrm{Al}$-Beta(66-48) $<m \mathrm{Al}-\mathrm{Beta}(66-113)$ for terpinenes, Al-Beta(55) $<m \mathrm{Al}-\mathrm{Beta}(66-113)<m \mathrm{Al}-$ Beta(66-48) for terpinolenes and $m$ Al-Beta $(66-48)<$ $m$ Al-Beta(66-113) $<$ Al-Beta(55) for HRTPs. The data support the idea that at high $\alpha$-pinene conversion levels, limonene isomerizes to terpinolenes and terpinenes and they are further transformed into HRTPs [24]. The amount of HRTPs is found to be the highest over Al-Beta(55) sample. The pores of the latter, within the range $200-100 \AA$, are about $51.6 \%$, whereas for both meso-Beta samples almost the same percentage corresponds to pores with radius of 10-20 А.

The typical kinetic curves are presented in Fig. 2. The main reaction products are camphene, terpinenes, terpinolenes and HRTP over Al-Beta(55) and meso-Beta zeolites. It is perceived that when $\alpha$-pinene is consumed, camphene slowly undergoes isomerization to tricyclene, finally achieving equilibrium concentration. At high conversion

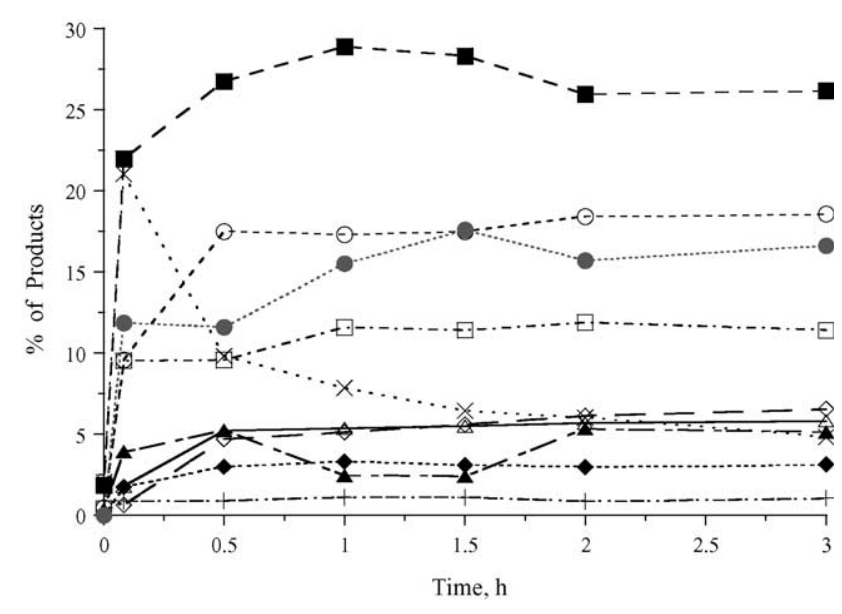

Fig. 2. Product distribution in $\alpha$-pinene isomerization over meso-Beta(66$48)$ at $100{ }^{\circ} \mathrm{C}:(\boldsymbol{\square})$ camphene; $(\Delta)$ tricyclene; $(\boldsymbol{\Delta})$ fenchenes; $(\times)$ limonene; $(\bigcirc)$ terpinenes; $(\square)$ terpinolenes; $(\bullet)$ HRTP; $(\diamond)$ p-cymene; (+) LRTP; $(\diamond)$ UP.

levels of $\alpha$-pinene, limonene isomerizes into secondary products such as terpinenes and terpinolenes. HRTPs are produced as a result of disproportionation reactions of terpinenes and terpinolenes.

The reaction of $\alpha$-pinene isomerization is found to be of first order by many authors [1,6,12,25]. A first order dependency on $\alpha$-pinene consumption is used in our experiments to calculate the rate constant of the reaction too. The vigorous stirring is applied to eliminate the external diffusion resistance between the bulk liquid and the catalyst

Table 3

Dependence between Beta zeolites composition and the rate constant of $\alpha$ pinene isomerization

\begin{tabular}{llc}
\hline Zeolite & Composition & Rate constant $\left(\mathrm{h}^{-1}\right)$ \\
\hline B-Beta(20) & $\mathrm{SiO}_{2} / \mathrm{B}_{2} \mathrm{O}_{3}=20$ & $9.065 \times 10^{-3}$ \\
Al-Beta(20) & $\mathrm{SiO}_{2} / \mathrm{Al}_{2} \mathrm{O}_{3}=20$ & $22.630 \times 10^{-3}$ \\
Al-Beta(55) & $\mathrm{SiO}_{2} / \mathrm{Al}_{2} \mathrm{O}_{3}=55$ & 2.232 \\
Al-Beta(130) & $\mathrm{SiO}_{2} / \mathrm{Al}_{2} \mathrm{O}_{3}=130$ & $2.128 \times 10^{-3}$ \\
Ti-Beta(130) & $\mathrm{Ti} / \mathrm{Al}^{-3}$ & $2.544 \times 10^{-3}$ \\
V-Beta(20) & $\mathrm{Si} / \mathrm{V}=45$ & $9.645 \times 10^{-3}$ \\
Al-Beta(66) & $\mathrm{SiO}_{2} / \mathrm{Al}_{2} \mathrm{O}_{3}=66$ & $6.675 \times 10^{-3}$ \\
$m$ Al-Beta(66-48) & $\mathrm{SiO}_{2} / \mathrm{Al}_{2} \mathrm{O}_{3}=66$ & 2.271 \\
$m$ Al-Beta(66-113) & $\mathrm{SiO}_{2} / \mathrm{Al}_{2} \mathrm{O}_{3}=66$ & 2.385 \\
\hline
\end{tabular}


surface. The turbulence created by nitrogen stream around the catalyst particles also helps to eliminate the external diffusion resistance. Due to the small size of catalyst particles (powder form), the internal diffusion resistance is considered to be negligible as well. The values of the first order rate constants calculated by least square techniques for all catalysts are presented in Table 3. As it is seen, the catalytic activity changes dramatically with the zeolite composition. The maximum rate was measured on the sample with a module of $\mathrm{SiO}_{2} / \mathrm{Al}_{2} \mathrm{O}_{3}=55$. Incorporation of boron, vanadium or titanium in Beta zeolite framework decreases the catalytic activity sharply. This is probably due to the very low acid strength of proton on boron, vanadium or titanium site. The methods of Beta zeolite synthesis also have no significant effect on the catalytic activity.

\section{Conclusion}

The isomerization of $\alpha$-pinene has been confirmed to take place on the Brönsted acidic centres of the different Beta zeolites. Depending on the method of synthesis and template removal, bimodal Beta samples with an appropriate balance between the Brönsted acidic centres and the pores could be obtained and used for a complete conversion of $\alpha$-pinene. Beta samples with a $\mathrm{SiO}_{2} / \mathrm{Al}_{2} \mathrm{O}_{3}$ module of about 55-66 and containing both micro- and mesopores display a high catalytic activity. Beta samples with boron, titanium or vanadium, as lattice ions do not possess significant catalytic activity in the liquid phase isomerization of $\alpha$-pinene most probably due to the difficult accessibility of the acid sites.

\section{Acknowledgements}

Funding for this work from Turkish Scientific Research Council through Grant MISAG-Bulgaria 1 and from the Turkish-Bulgarian inter-academic exchange agreement is gratefully acknowledged. The authors thank Burcu Atalay and Hilal Güleç for isomerization runs.

\section{References}

[1] F. Özkan, G. Gündüz, O. Akpolat, N. Beşün, D. Yu Murzin, Chem. Eng. J. 91 (2003) 257, and references therein.

[2] L. Grozona, N. Comelli, O. Massini, E. Ponzi, M. Ponzi, React. Kinet. Catal. Lett. 69 (2) (2000) 271.

[3] C.M. Lopez, F.J. Machado, K. Rodriguez, D. Arias, B. Mendez, M. Hasagawa, Catal. Lett. 221 (1999) 62.

[4] N. Beşün, F. Özkan, G. Gündüz, Appl. Catal. A: Gen. 224 (2002) 285.

[5] G. Gündüz, D. Yu Murzin, React. Kinet. Catal. Lett. 75 (2) (2002) 231.

[6] A. Severino, A. Esculcas, J. Roche, J. Vital, L.S. Labo, Appl. Catal. A: Gen. 142 (1996) 255

[7] O. Akpolat, G. Gündüz, F. Özkan, N. Beşün, Appl. Catal. A: Gen. 265 (2004) 11.

[8] I. Kiriesi, C. Flego, G. Pazzuconi, J. Phys. Chem. 98 (1994) 4624.

[9] M. Muller, G. Harvey, R. Prins, Micropor. Mesopor. Mater. 34 (2000) 135.

[10] R. Dimitrova, G. Gündüz, L. Dimitrov, T. Tsoncheva, S. Yılmaz, E.A. Urquieta-Gonzalez, J. Mol. Catal. A: Chem. 214 (2004) 265.

[11] G. Gündüz, R. Dimitrova, S. Yılmaz, L. Dimitrov, M. Spassova, J. Mol. Catal. A: Chem. 225 (2005) 253.

[12] J.C. Vander Waal, H. Bekkum, J.M. Vital, J. Mol. Catal. A: Chem. 105 (1996) 185.

[13] P.J. Kunkeler, J.C. Vander Waal, J. Bremmer, B.J. Zuurdeeg, R.S. Downing, H. Van Bekkum, Catal. Lett. 53 (1998) 135.

[14] J.C. Vander Waal, P. Lin, M.S. Rigutto, H. Van Bekkum, Stud. Surf. Sci. Catal. 105 (1997) 1093.

[15] J.C. Vander Waal, H. Van Bekkum, J. Mol. Catal. A: Chem. 124 (1997) 137.

[16] C. Zhang, Q. Liu, Z. Xu, K. Wan, Micropor. Mesopor. Mater. 62 (2003) 157.

[17] K. Hensen, C. Mahaim, W.F. Hölderich, Appl. Catal. A: Gen. 149 (1997) 311.

[18] U. Lohse, B. Altrichter, R. Donald, R. Fricke, K. Jansen, B. Parlitz, E.J. Schreler, J. Chem. Soc., Faraday Trans. 92 (1996) 159.

[19] M. Matsukate, T. Osaki, M. Oggura, E. Kikuchi, Micropor. Mesopor. Mater. 56 (2002) 1.

[20] L. Liu, W. Zhang, T.J. Pinnavaia, Angew. Chem. 113 (7) (2001) 1295.

[21] M.M. Dubinin, V.A. Astakhov, Adv. Chem. Ser. 102 (1970) 69.

[22] J.J. Gregg, K.J.W. Sin, Adsorption, Surface Area and Porosity, Academic Pres, New York, 1982, 197.

[23] R. Dimitrova, Y. Neinska, M. Mihalyi, T. Tsoncheva, M. Spassova, React. Kinet. Catal. Lett. 74 (2001) 353.

[24] C.M. Lopez, F.J. Machado, K. Rodriguez, B. Mendez, M. Hasegawa, S. Pekerar, J. Appl. Catal. A: Gen. 173 (1998) 75.

[25] A.I. Allahverdiev, S. Irandoust, D. Yu Murzin, J. Catal. 185 (1999) 352. 